\title{
Uma pálida neblina: paisagem e melancolia no cinema italiano moderno
}

\author{
Ângela Freire Prysthon' \\ I - UFPE \\ Recife (PE), Brasil
}

Resumo: A partir de um panorama conceitual sobre a paisagem no cinema, que implica na distinção entre uma concepção cênica e territorializada em contraposição a uma função mais contemplativa e material do espaço, o objetivo desta apresentação é analisar quatro filmes de ficção italianos ambientados no Delta do Pó - "O grito" (1957) e "O deserto vermelho" (1964), de Antonioni; "A noite do massacre" (1960), deVancini; e "O jardim dos Finzi-Contini" (1970), de de Sica. Esse pequeno conjunto, marcado por sua aderência ao cinema moderno italiano, revela também uma unidade pictórica. Nossa hipótese inicial é que a ambiência e a formação de estilo são simultaneamente determinadas e condensadas por características da paisagem na qual os filmes são localizados. Para desenvolver essa hipótese e para a análise baseio-me tanto no lastro teórico dos estudos da paisagem como em abordagens mais pontuais sobre a ambiência e a espacialidade no cinema moderno, além, evidentemente, da literatura sobre o cinema italiano moderno.

Palavras-chave: paisagem; melancolia; cinema italiano moderno.

Abstract: A pale mist: Landscape and melhancholy in the modern Italian cinema - From a conceptual panorama on the landscape in the cinema, which implies the distinction between a scenic and territorialized conception as opposed to a more contemplative and more material function of space, the purpose of this paper is to analyse four Italian fiction films set in the Po Valley - "Il grido" (1957) and "Deserto Rosso" (1964) by Antonioni, "La lunga notte del '43"(1960) by Vancini and "Il giardino dei Finzi-Contini" (1970) by de Sica. This collection, marked by its adherence to the modern Italian cinema, reveals a pictorial unity. Our initial hypothesis is that this ambience and the formation of style are simultaneously determined and condensed by characteristics of the landscape in which the films are located. In order to develop this hypothesis and to analyse the films, I adopt the theoretical framework of landscape studies, as well as on specific approaches to modern cinema, and the literature on modern Italian cinema.

Keywords: landscape; melancholy; modern italian cinema. 


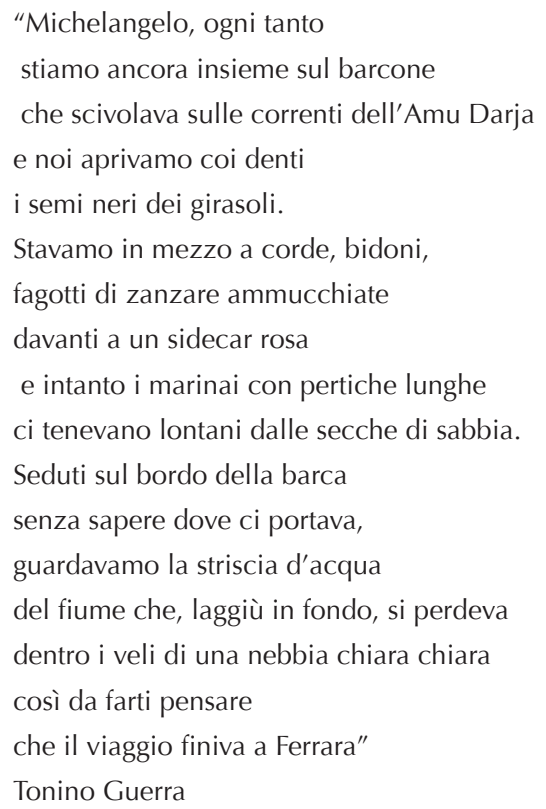

Na Anunciação (1472-1475) do jovem Leonardo da Vinci (figs. 1 e 2) somos instados a olhar para a paisagem como algo que vai além da sua função usual de cenário. Sim, ela ainda é pano de fundo e secundária com respeito às figuras do anjo e de Maria. Contudo, a construção espacial, as árvores na distância, a água do rio e a pálida neblina insinuada no sfumato nas montanhas contribuem para que a paisagem transcenda sua função de ornamento. Há maestria em transformar um detalhe periférico em um foco pictórico relevante, em uma pista para a compreensão da geografia (real e imaginária) do século XV e dos modos de representação espacial na pintura. De certa maneira, uma pintura como essa (entre muitas outras de Leonardo e de outros artistas anteriores e posteriores a ele) confirma a existência da "paisagem antes da paisagem", ou seja, antes da existência do gênero específico emergido nos países baixos por volta do século XVII. Se mesmo nos afrescos da Antiguidade Clássica podemos intuir uma espécie de proto-paisagem enquanto gênero pictórico, no Renascimento sua importância foi se expandindo, a composição espacial tornava-se cada vez mais crucial para dar consistência às figuras, aos temas dos quadros. 

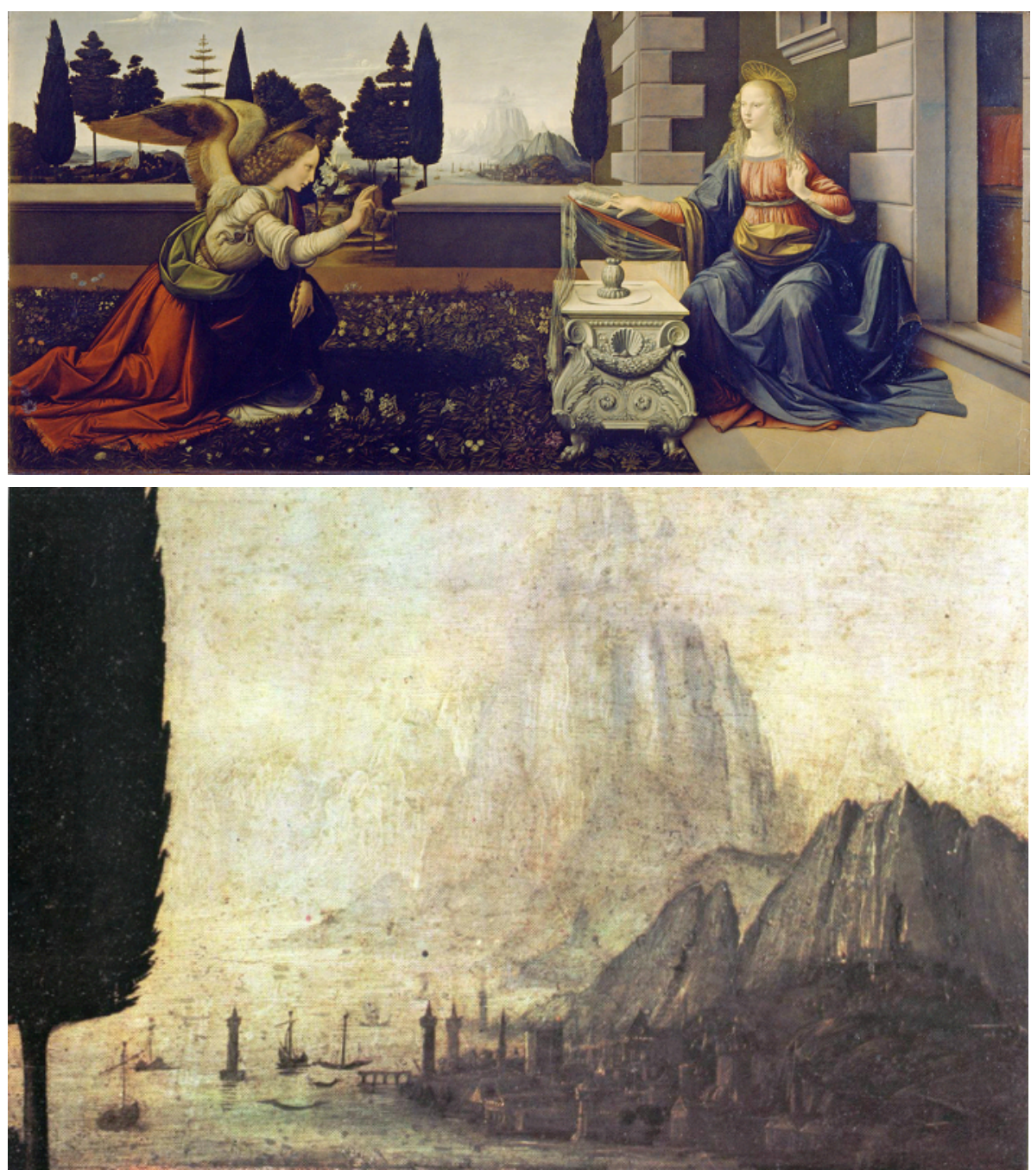

Fig.1. A anunciação (Leonardo da Vinci)

Fig.2. Detalhe (Leonardo da Vinci)

Se a pintura holandesa do século XVII inaugura no Ocidente o gênero paisagem nas artes visuais, o romantismo alemão do final do século XVIII, assim como a estética, consolidam a paisagem como elemento fundamental para o conceito de sublime e para a constituição da ideia de mood, de ambiência. Ou seja, a natureza como uma força quase irrepresentável, "uma sorte de horror delicioso" (ANDREWS, 1999, p.130), como é possível vislumbrar na obra de Caspar David Friedrich (fig. 3), por exemplo. A pintura romântica alemã nos parece essencial para vislumbrar os novos elos entre paisagem 
e figura humana em outros termos: a paisagem deixa realmente de ser pano de fundo para efetivamente transformar o sujeito contemplativo, para afetá-lo de modo indelével. A paisagem cada vez mais como parte ativa na relação do humano com o mundo (natural e construído). A liberdade na pintura do século XIX [Turner (fig. 4) no início do século e os impressionistas no final talvez sejam os melhores exemplos] e do século XX levou a paisagem a limites abstratos. E a evolução da fotografia impactou tremendamente nossas formas de percepção da paisagem, principalmente a partir da conexão entre fotografia e turismo (a indústria de cartões postais de vistas pitorescas, por exemplo), fotografia e arqueologia, fotografia e mundo natural etc.
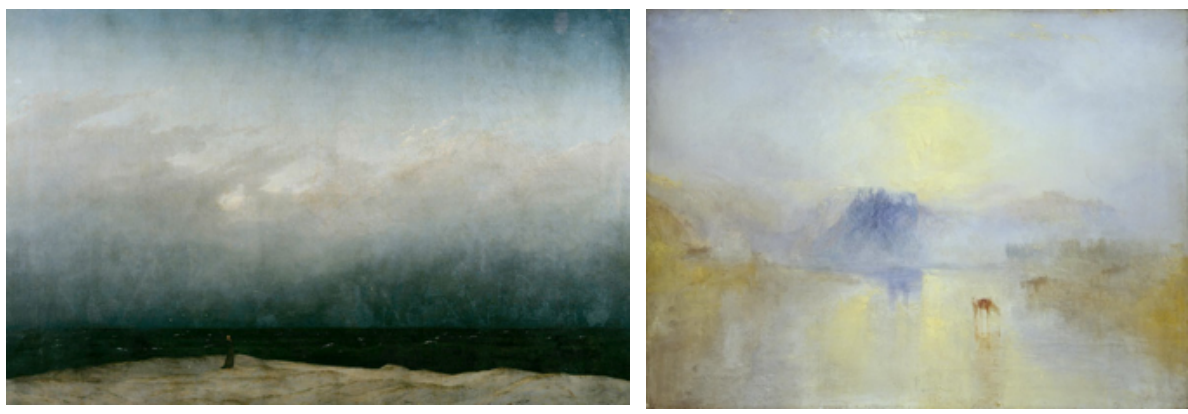

Fig.3. Monge à beira mar (Caspar David Friedrich, 1808-1810); Fig.4. Norham Castle, Sunrise (Joseph Mallord William Turner, 1845

Jean-Luc Nancy acessa a paisagem via etimologia, vendo nas declinações dos termos franceses pays, paysan e paysage uma combinação estrutural (um semantema) que definiria modos de apreender e representar o espaço:

The location, occupation, and representation of a single reality. This reality would be nothing other than what is indicated by the Latin origin of the word pays: pacus or pagus, the canton, that is, again — and this time in conformity with the word canton itself — a "corner" of land. (NANCY, 2005, p. 51) ${ }^{1}$

John Stilgoe (1980, p.3) também menciona essa noção do "canto", do pedaço, definido por uma condição compacta e por uma transformação do mundo natural. Uma certa "domesticação" do espaço, uma humanização da natureza. Ambos os autores fazem referência à centralidade que a pintura holandesa do século XVII teve na disseminação do termo e da própria ideia de paisagem.

1 "A locação, a ocupação e a representação de uma realidade única. Essa realidade não seria outra coisa que o que está indicado na origem latina da palavra pays (país): pacus ou pagus, o cantão, ou seja, novamente - e dessa vez em conformidade com a própria palavra cantão - um "canto", uma "esquina" de terra". (Tradução nossa) 


\section{O cinema, a paisagem autônoma e o Stimmung da melancolia}

A noção de paisagem no cinema é baseada nos mesmos princípios que regulam suas acepções tanto nas artes (representação) como nas ciências naturais e humanas (paisagem como o mundo "real", como o mundo natural). Martin Lefebvre fala desse duplo sentido do termo:

It can refer to a pictorial genre (and the individual works that comprise it), but it can also refer to actual views of a "real," natural, exterior space. In other words, it refers at times to the pictorial representation of a space and at other times to the real perception of a space. (LEFEBVRE, 2006, p. 20)²

Implícita então nessa dupla natureza do termo está também a bifurcação que se dá entre um cinema que associa a paisagem a um cenário e aquele no qual a paisagem passa a ocupar uma centralidade quiçá inesperada, adquirindo uma certa autonomia com relação à narrativa. Ou, às vezes, dependendo da paisagem para que as narrativas se desenrolem. Pensemos, por exemplo, como alguns gêneros cinematográficos são mais propícios que outros a essa conexão com a paisagem: o western, o road movie, o travelogue documentário, o épico, o cinema de época. Mas mesmo em gêneros pouco afeitos à paisagem, como o filme noir ou a comédia romântica, algo escapa, algo explode. Como aponta Kracauer com relação às "pequenas unidades" de existência material contingente (rostos, espaços, detalhes) capturadas pela imagem fílmica, tais unidades "abrem uma dimensão muito mais ampla do que aquela dos enredos que elas sustentam" (KRACAUER, 1997, p. 303).

No entanto, são algumas recorrências estéticas do cinema moderno que enfaticamente reforçam o nexo com uma poética do lugar, com uma afirmação particular do espaço e com uma perspectiva mais complexa em relação à topofilia fílmica. Podemos pensar no neorrealismo como um marco relevante para a intensificação das possibilidades da paisagem autônoma. Deleuze percebia isso como a emergência da imagem-tempo, na qual

as situações óticas e sonoras do neorrealismo se opõem às situações sensóriomotoras fortes do realismo tradicional". [...] As imagens óticas e puras, o plano fixo e a montagem-cut definem e implicam um para além do movimento. [...] Fazem com que o movimento não seja percebido numa imagem sensório-motora, mas apreendido e pensado em outro tipo de imagem. (1990, p. 14 e 33)

Podemos pensar no neorrealismo como um marco relevante para a intensificação das possibilidades da paisagem autônoma. De certa forma, o neorrealismo inaugura uma linhagem de paisagismo cinematográfico que nos leva a associações imediatas a nomes como Michelangelo Antonioni, Wim Wenders ou Andrei Tarkovsky. Outros nomes também

2 "(A paisagem) pode se referir a um gênero pictórico (e às obras individuais compreendidas por ele), mas também pode se referir a uma vista de um espaço "real", natural e exterior. Em outras palavras, refere-se às vezes a uma representação pictórica do espaço e em outras à real percepção de um espaço." (Tradução nossa) 
podem ser enumerados com relação à composição de paisagens cinematográficas e revelam geografias afetivas igualmente interessantes. Como a topografia australiana de Peter Weir em Picnic at Hanging Rock (1975), que combina certa delicadeza despreocupada com mistério gótico. Ou aquela apresentada por Werner Herzog em Herz Aus Glas (1976), na qual a Bavária do século XVII é apresentada sob a inspiração da pintura de Caspar David Friedrich. Também a Sardenha dos irmãos Taviani e a forma como ela é desenhada em Padre Padrone (1977), sempre ligada a um passado opressivo e estagnante. E ainda a Lisboa de Alain Tanner em Dans la ville blanche (1983), na qual composições marítimas e vistas pitorescas contrastam com a introversão silenciosa do protagonista.

O universo paisagístico do cinema moderno traz à tona também uma recorrência conceitual: a ideia de Stimmung (mood, atmosfera ou ambiência) e mais particularmente uma tonalidade sombria para essa noção. O Stimmung cinematográfico não está associado apenas à paisagem, mas a um conjunto de elementos variados que envolvem imagens e sons, enquadramentos e elementos de mise-en-scène.

Stimmung, for Eisner, citing the German romantic poet Novalis, evokes a 'musical condition of the soul', encompassing both 'psychical acoustics and the harmony of vibrations'; an atmosphere elicited principally by the expressionist play of light and shadow. (SINNEBRINK, 2012, p. 149)

Não raro nos filmes modernos (em especial os europeus), vamos nos deparar com uma associação entre espaço e melancolia, entre uma consciência do lugar e uma espécie de tristeza original. Falando sobre Caspar David Friedrich, Gumbrecht faz uma conexão entre o sublime despertado pela natureza e uma sensação de inadequação, de desprazer, talvez despertada pela própria ânsia de harmonia e adequação ao mundo:

Não deveríamos, portanto, tentar reduzir as paisagens de Friedrich à fórmula única da harmonia entre o homem e a natureza. Ao contrário, natureza e homem devem ser entendidos em termos de um espectro de perspectivas do observador, que vai, por um lado, da bela harmonia das figuras devidamente ajustadas até o desprazer sublime experimentado quando da libertação que ocorre entre a natureza e o observador, por outro. (2014, p. 90)

Essa inadequação ou, dizendo melhor, a vaga má sensação da experiência do sublime paisagístico no cinema moderno está quase que invariavelmente associada à melancolia. Há uma inequívoca preponderância melancólica na cartografia paisagística do cinema moderno: vistas invernais, ruínas, indústrias, chuva, neblina, desertos, figuras solitárias na cidade ou em lugares desolados. Todo esse imaginário alude à paisagem como lugar de contemplação, de luto, de memória e de tristeza. Jacky Bowring fala desse contato com

3 "Stimmung, para (Lotte) Eisner, citando o poeta romântico alemão Novalis, evoca uma 'condição musical da alma', abrangendo tanto a 'acústica psíquica quanto a harmonia das vibrações'; uma atmosfera suscitada principalmente pelo jogo expressionista de luz e sombra." (Tradução nossa) 
a paisagem como uma solidão produtiva posta em marcha pela melancolia e pela acídia: "The paradox of a beauty founded in sorrow, a love of loss, of longing, is melancholy's gift to aesthetics." (2017, p. 18)

\section{Dois ferrarenses e um rio}

Esse rápido preâmbulo nos fornece pistas para começar a abordar a evidente unidade encontrada em um conjunto de filmes que vai do final da década de 50 até o início dos anos 70: quatro filmes de ficção ambientados na região da Emilia-Romagna - O grito (Il grido, 1957) e O deserto vermelho (II Deserto Rosso, 1964), de Michelangelo Antonioni; A noite do massacre (La lunga notte del '43, 1960); de Florestano Vancini e; O jardim dos Finzi Contini (II giardino dei Finzi Contini, 1970), de Vittorio de Sica. Antes, porém, de começar a descrevê-los, com o intuito de compor um mapeamento pictórico da paisagem do cinema moderno italiano, talvez seja pertinente começar por dois filmes documentais que precedem o conjunto e sugerem certos padrões audiovisuais relacionados tanto com a geografia do Norte da Itália como o tom melancólico que caracteriza o nosso corpus.

Na sua estreia como diretor, o ferrarense Michelangelo Antonioni filma o curta Gente del Po, quase na mesma época (foi filmado em Porto Tolle em 1943 e concluído após a guerra em 1947) e a poucos quilômetros de distância da realização do filme pioneiro do neorrealismo, Ossessione (1943), de Luchino Visconti. Esse pequeno documentário já estabelece muito enfaticamente as conexões com o espaço geográfico do Delta do Pó na sua obra (e de certo modo no cinema italiano como um todo). Se a "gente" do título indica uma espécie de intenção etnográfica, vai se tornando claro logo nos primeiros dos pouco mais de dez minutos do filme que a etnografia é condicionada pelo ambiente, que os personagens estão marcados pela paisagem que se impõe como moldura e elemento produtor de forma e unidade. As maneiras a partir das quais Antonioni filma o rio (figs. 5 e 6), suas margens, a planície, sua parca vegetação e sua arquitetura precária formam uma sorte de matriz audiovisual para a região. Sandro Bernardi se refere às distinções entre Ossessione e Gente del Po como cruciais para compreender duas formas de filmar e conceber o espaço:

E mi sembra effettivamente importante ricordarlo, perchè si tratta di due forme di cinema profondamente differenti che nascono contemporaneamente dal neorealismo, una accanto all'altra: quella che proporrei di chiamare la linea del paesaggio come spazio mitico (Visconti costruisce narrazione di tipo tragico) e quella opposta, del paesaggio come luogo senza mito e senza centro (Antonioni). In Gente del Po incontriamo le prime impercettibili fratture, che sono aperture dentro il discorso, come la tendenza dela cinepresa ad abbandonare le figure appena sembrano assumere uma certa consistenza esprime già la volontà di non illudere lo spettatore con una storia, ma di rispettare l'intimità, l'estraneiài delle

4 "O paradoxo de uma beleza fundada na tristeza, um amor pela perda, pelo anseio, esse é o presente da melancolia à estética. " (Tradução nossa) 
figure che appaiono e scompaiono prima di diventare personaggi, dato che il personaggio è finzione. (BERNARDI, 2002, p.131)

De um modo parecido, quase como continuação desse registro do rio Pó, outro ferrarense, Florestano Vancini, com Delta Padano (1951) retoma a mesma moldura (figs. 7 e 8), redesenhando a topografia iniciada por Antonioni. Assumindo um tom mais narrativo (e curiosamente bem mais etnográfico que Gente del Po), Vancini confirma algumas recorrências pictóricas do filme do seu conterrâneo, ainda que atenuando o olhar melancólico e intensificando um pendor melodramático (a pobreza, a doença, a solidão são evocadas nos dois filmes), em uma certa medida sugerindo que Vancini se encontraria em um meio termo entre a paisagem como mito e a paisagem sem centro e sem mito.
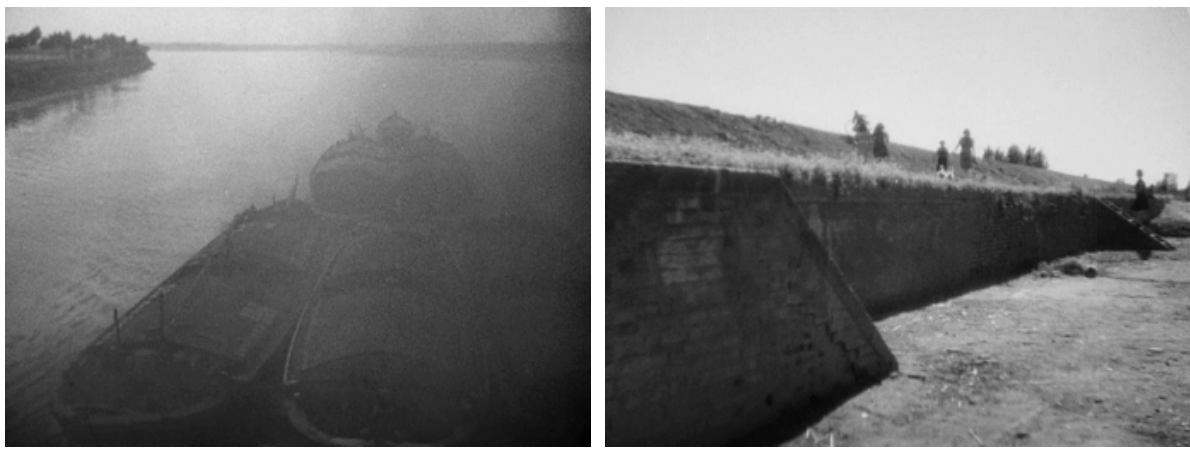

Figs.5 e 6. Gente del Po
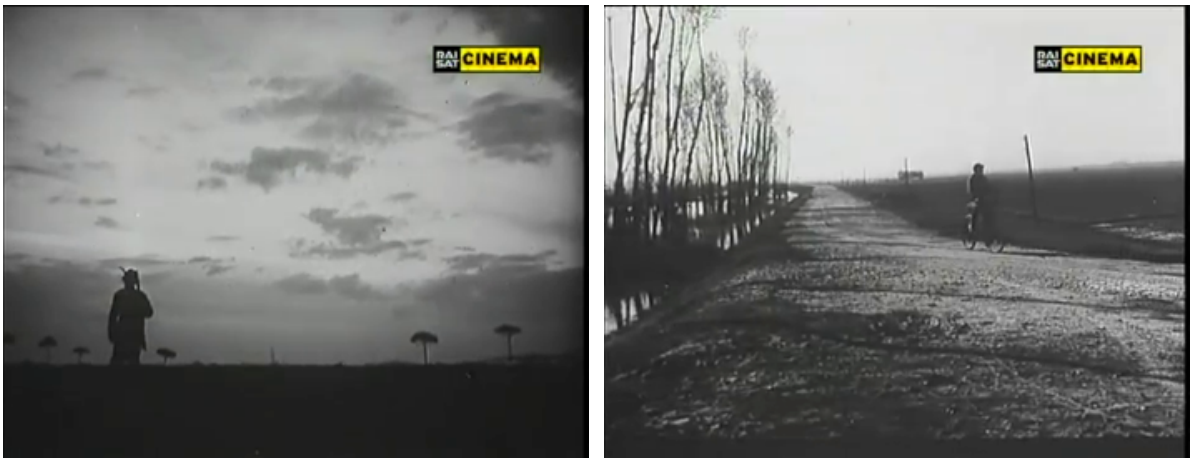

Figs. 7 e 8. Delta Padano

5 "Parece-me realmente importante lembrar, porque essas são duas formas de cinema profundamente diferentes que surgem simultaneamente do neorrealismo, uma ao lado da outra: o que eu sugeriria para chamar linha da paisagem como espaço mítico (Visconti constrói uma narrativa de um tipo trágico) e o oposto, da paisagem como um lugar sem mito e sem um centro (Antonioni). Em Gente del Po encontramos as primeiras imperceptíveis fraturas, que são aberturas dentro do discurso, como a tendência da câmera para abandonar as figuras assim que assumem uma certa consistência já expressa a vontade de não enganar o espectador com uma história, mas para respeitar a intimidade, a estranheza das figuras que aparecem e desaparecem antes de se tornar personagens, já que o personagem é ficção." (Tradução nossa) 
Embora outros filmes tenham retratado o Delta do Pó nas décadas de 40 e 50 (como, por exemplo, o já citado Ossessione, o último episódio de Paisà (1946), de Roberto Rossellini - também filmado em Porto Tolle -, ou os melodramas // mulino del Po (1949), de Alberto Lattuada e La donna del fiume (1955), de Mario Soldati, o próprio Antonioni em algumas partes de Cronaca de un amore (1950), entre outros), penso na dupla de documentários como um ponto de partida mais sólido para começar a elaborar sobre o papel da planície padana e arredores no cinema italiano pós-neorrealista. Em ambos, são destacadas algumas das características mais proeminentes da paisagem: seus pântanos rasos, seus canais, seu estuário de ilhas e dunas, suas fileiras de choupos e um pouco da névoa que será mais intensa ainda nos filmes de ficção. Tais características, além de moldarem um arranjo pictórico comum, colaboram com a formação de uma tonalidade afetiva marcada pela melancolia.

\section{Figuras na neblina}

O grito é o primeiro longa de Antonioni a elaborar de modo mais concreto as relações com a paisagem. Embora seus filmes anteriores já trouxessem à tona um diálogo enfático entre atores e espaços - algo que reflete seu interesse pelo desenho de cenários na adolescência e juventude (CHATMAN \& DUNCAN, 2004, p. 25) -, é nessa obra que efetivamente a representação do espaço adquire uma importância equivalente à da presença da figura humana. Com um plot bastante simples, no qual um operário é abandonado pela mulher e parte em deambulação com a filha pelo Vale do Pó, tentando sem sucesso novas relações com outras mulheres, O grito consolida a assinatura estilística de Antonioni.

Bernardi (2002, p. 148) percebe que n'O grito, Antonioni se propõe a revisitar os mesmos lugares de Ossessione (rio, estradas, margens, vegetação, casinhas pobres), mas que estes, ao contrário da sensualidade solar que permeia o filme de Visconti, estão transformados pela luz invernal e, especialmente, pela neblina. De fato, a neblina é um componente crucial no desenvolvimento não apenas desse filme específico, mas do próprio estilo de Antonioni. Em uma entrevista apresentada como "extra" do DVD de Identificazione di una donna (Antonioni, 1982), o roteirista e poeta Tonino Guerra faz uma conexão explícita entre ser originário da Emilia-Romagna e estar habituado a ver através da neblina. Para ele cineastas como Antonioni e em outro sentido também Fellini (de Rimini) poderiam utilizar a imagem da névoa como uma alegoria da incomunicabilidade, com esse forte sentido de indefinição do que está à frente ou atrás. Os personagens d'O grito estão envoltos em bruma. Desde os primeiros minutos d'O grito (figs. 9 a 11), a neblina é a fonte de um elo muito forte com Ferrara e seus arredores, conhecidos por uma névoa insistente que chega a cobrir a região por cinco ou seis meses por ano. Mais ainda, funciona como uma materialização metafórica da melancolia, da distância e do laconismo entre os personagens e de uma subjetividade obnubilada - todas unidades 
constituintes da sua filmografia posterior. No início do filme, Irma (Alida Valli), mulher de Aldo (Steve Cochrane), o protagonista, parece utilizar a neblina como esconderijo, como trilha de fuga. Por outro lado, Aldo vagueia em um mundo cinzento e obscuro no qual as forças da natureza reverberam seu estado de ânimo.

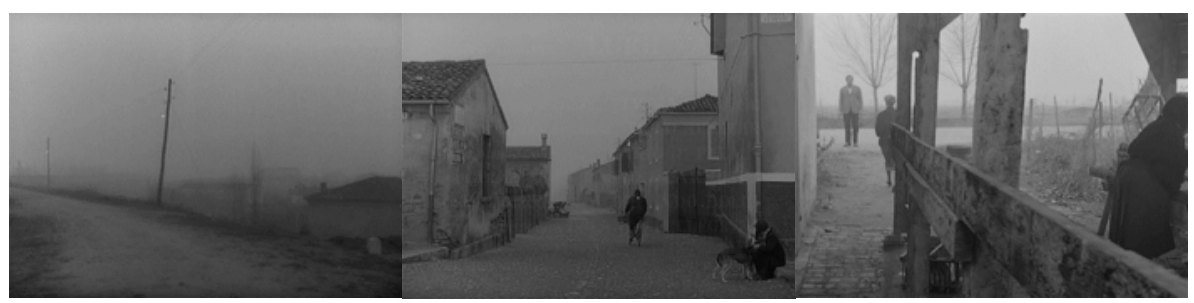

Figs. 9 a 11: O grito

Porém não são apenas as imagens de neblina e as formas através das quais elas refletem a tragédia de Aldo que definem o Stimmung d'O grito. Há no filme um exercício muito consciente de rigor geométrico, um uso deliberado e pronunciado de perspectivas e simetrias. As cenas iniciais e finais na fábrica, por exemplo, demonstram a uma só vez o engajamento do diretor com formas clássicas de enquadramento e um olhar profundamente modernista, de certa maneira remetendo ao uso que De Chirico faz da perspectiva renascentista (figs. 12 a 14). O grito foi, portanto, o ponto de partida para que Antonioni se pusesse a elaborar a rigorosa arquitetura espacial que o caracterizou e que talvez tenha alcançado seu ápice em O Eclipse (1962), especialmente se consideramos o jogo entre linhas e perspectivas. Em suma, esse filme é o exercício mais estruturado antes de Antonioni se tornar conhecido como um cineasta do espaço.

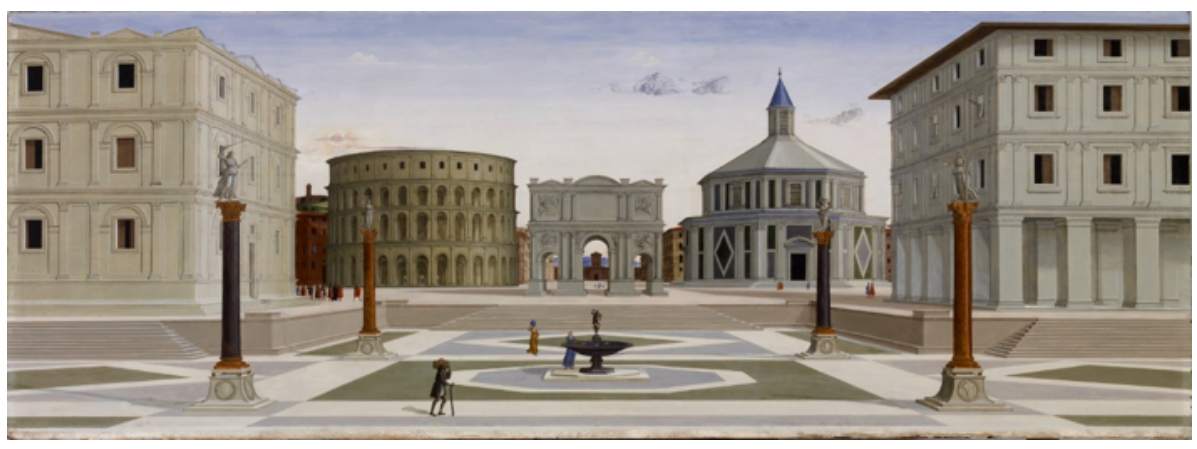

Fig. 12. atribuída a Fra Carnevale (c.1480-1484) 

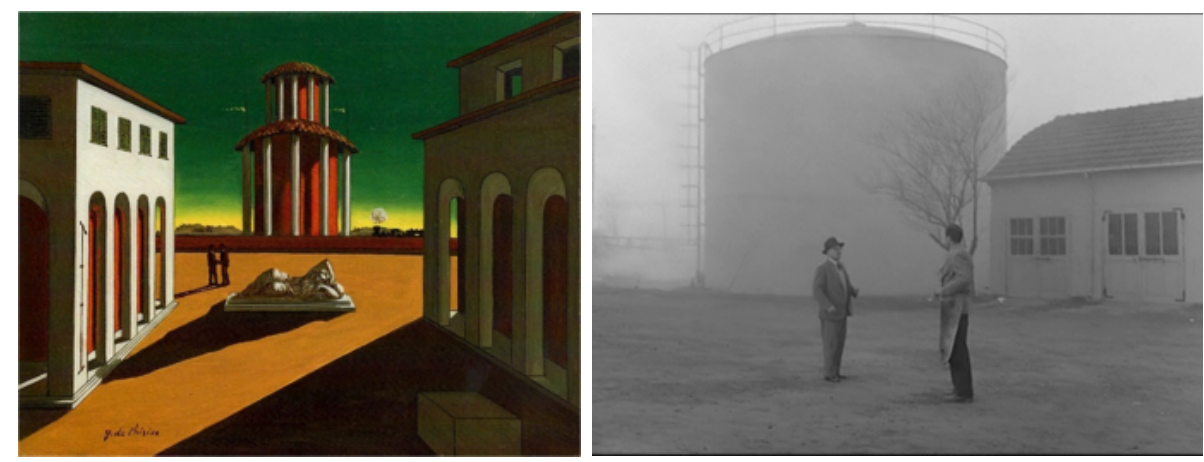

Fig. 13. Piazza d'Italia (De Chirico, 1913); fig. 14: O grito

\section{A longa noite de sombras e neblina}

Em um registro bem mais convencional e narrativo que $O$ grito, o segundo filme do nosso conjunto, o melodrama histórico $A$ noite do massacre, é uma adaptação de um dos contos de Cinque storie ferrarese, de Giorgio Bassani (MICALLIZZI, 2002, p. 47), baseado por sua vez em um evento real ocorrido em Ferrara, na Segunda Guerra Mundial, no dia 15 de novembro de 1943, no qual onze oponentes do fascismo foram fuzilados na frente do Castelo Estense, no centro da cidade. Com roteiro escrito por Pier Paolo Pasolini, Ennio De Concini e pelo próprio Florestano Vancini, o filme focaliza o caso de amor entre Anna, a jovem esposa do farmacista (e voyeur) inválido, e Franco, um ex-namorado que retornou à cidade após o armistício de setembro de 1943.

Apesar dessa maior aderência aos padrões do neorrealismo estabelecido (pensamos na articulação entre o melodrama hollywoodiano, a ficção histórica e a força das locações reais) e ao cinema comercial, $A$ noite do massacre deixa entrever tanto uma continuidade com relação a Delta Padano (as cenas às margens do Pó com seus habitantes têm uma força documental menos encenada que o próprio documentário - fig.15) como um vigor pictórico com relação às imagens da cidade de Ferrara e das paisagens padanas (figs. 16 a 20). É surpreendente também como, quando confrontamos os stills dos dois documentários, de $O$ grito e $A$ noite do massacre, há enormes coincidências de enquadramentos e ângulos, confirmando de certa maneira uma intuição de que a ambiência e a formação de tom e estilo são simultaneamente determinadas e condensadas por características da própria paisagem na qual os filmes são localizados. 


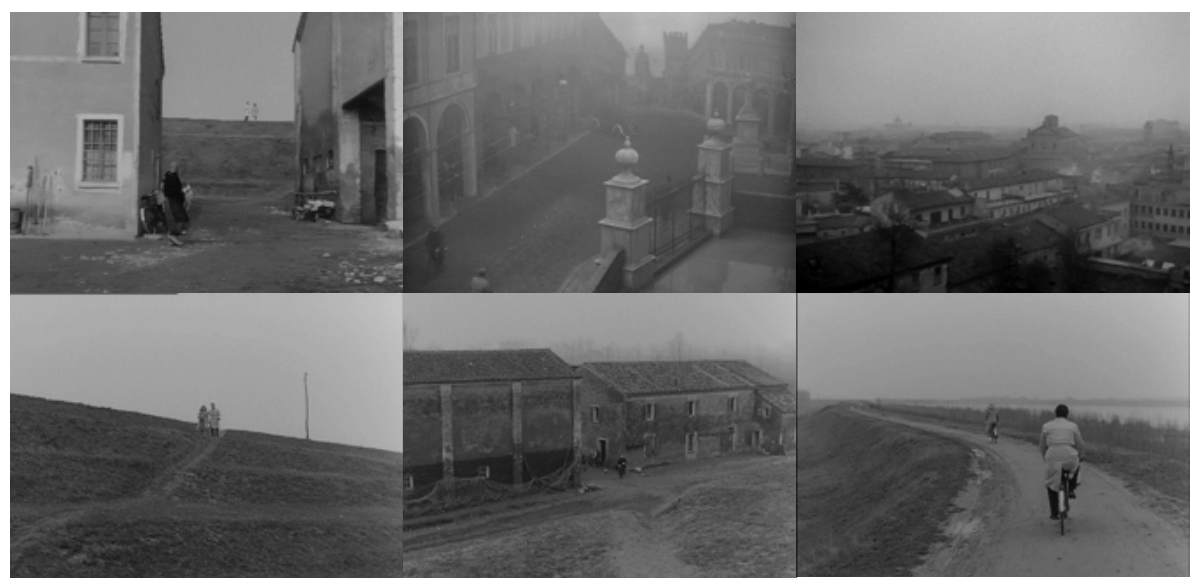

Figs. 15 a 20. A noite do massacre

Como o filme também é ambientado no outono, a conspícua neblina ferrarense provoca o mesmo efeito turvo, a mesma intensidade obscura e rasurada delineada pelo filme de Antonioni. À diferença deste, porém, não se tem uma imbricação tão evidente entre a iconografia paisagística, a mise en scène e as implicações psicológicas dos personagens e seus atos. A melancolia invocada nas imagens (principalmente aquelas de névoas e sombras) encontra mais correspondência no comentário político, na impotência diante dos fatos históricos que propriamente na atuação e nas intrigas do casal principal. O que não parece em absoluto retirar a profundidade da composição espacial e de como ela reverbera no filme. Muito ao contrário, se falta ao filme uma densidade na caracterização dos personagens (manifesta na repetição de clichês românticos, dos filmes de guerra, na banalidade dos diálogos e até na apresentação de vilões óbvios), o rigor pictórico e a consistência dos quadros evidenciam a potência mesma do ambiente, da locação e da geografia que acabam se impondo sobre o plot.

Nessa ascendência da topografia, a cidade de Ferrara ocupa um papel crucial em A noite do massacre. A austeridade da sede da dinastia d'Este com suas torres, fossos e ameias está na base do material fonte do filme (o conto de Bassani e a execução dos antifascistas), assim como na inscrição do espaço urbano e seus símbolos mais expressivos na obra de Vancini. Vistas do castelo Estense (fig.16), os personagens de bicicleta (Ferrara é conhecida por sua profusão de ciclistas) (fig.20); a escultura de Girolamo Savonarola (fig. 21), o cemitério de Certosa (fig. 22), as galerias sombreadas da Via Palestro em frente à Piazza Ariostea (fig.23), entre outros pontos muito marcados da cidade, não são meros panos de fundo, nem cenários inócuos, mas antes sobreposições à narrativa. Ao mesmo tempo também são parte de um contínuo espaço-tempo, composto de frames e um canal de memórias da cidade, uma forma do tempo que transcende o filme em si, aproximando esse aparente melodrama banal dos ímpetos do cinema moderno mundial. 


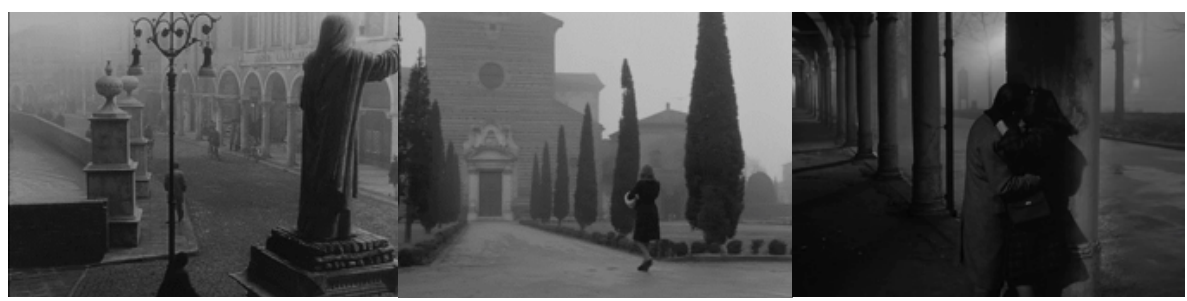

Figs. 21 a 23. A noite do massacre

\section{A paisagem transfigurada}

O Deserto Vermelho concerne Giuliana (Monica Vitti), uma dona de casa perturbada, recém-saída de uma clínica psiquiátrica após uma tentativa de suicídio, e seu envolvimento com Corrado (Richard Harris), velho amigo do seu marido que chega de longe com uma proposta de trabalho. Apesar do título, não há nenhum deserto real no filme, já que estamos na zona industrial de Ravenna, no mesmo território padano que caracteriza o recorte deste artigo (a não ser pela breve fábula contada por Giuliana a seu filho, localizada em uma praia idílica, cujo contraste não poderia ser maior com o ambiente inóspito e a aspereza da Emilia-Romagna retratada no filme). O filme prescinde de uma trama estruturada ainda mais em $O$ grito e nos parece uma intensificação da trilogia (ou às vezes é considerado parte de uma tetralogia) da incomunicabilidade formada por A aventura (1960), A noite (1961) e O eclipse (1962).

Primeiro filme de Antonioni em cores, O Deserto Vermelho é o caso mais peculiar do nosso conjunto por vários motivos. O primeiro deles diz respeito precisamente às formas meticulosas com as quais Antonioni trabalhou a cor. A ideia foi não apenas filmar em cores, mas alterar a aparência da realidade através da cor. Pintou árvores, grama, paredes, objetos, ruínas, cenários. Oscilou entre uma paleta bem saturada e outras esmaecidas e neutras, em uma deliberada e obsessiva busca por nuances de alienação e artificialidade através da cor: $O$ Deserto Vermelho é quase uma investigação pictórica com o casaco verde de Giuliana contrastando com o cinza dos muros da fábrica, o carro branco e as roupas escuras dos grevistas (fig. 24); o verde do muro que quase se confunde com o verde da grama e a roseira recém plantada (fig.25); o fundo desfocado de estruturas metálicas vermelhas emoldurando o rosto da protagonista (fig. 26); a cabana vermelha na qual os endinheirados de Ravenna fazem uma pequena orgia (fig. 27); o alto contraste entre pretos e brancos na cena no barco (fig. 28); e a fumaça amarela da fábrica no final do filme (fig.29). 


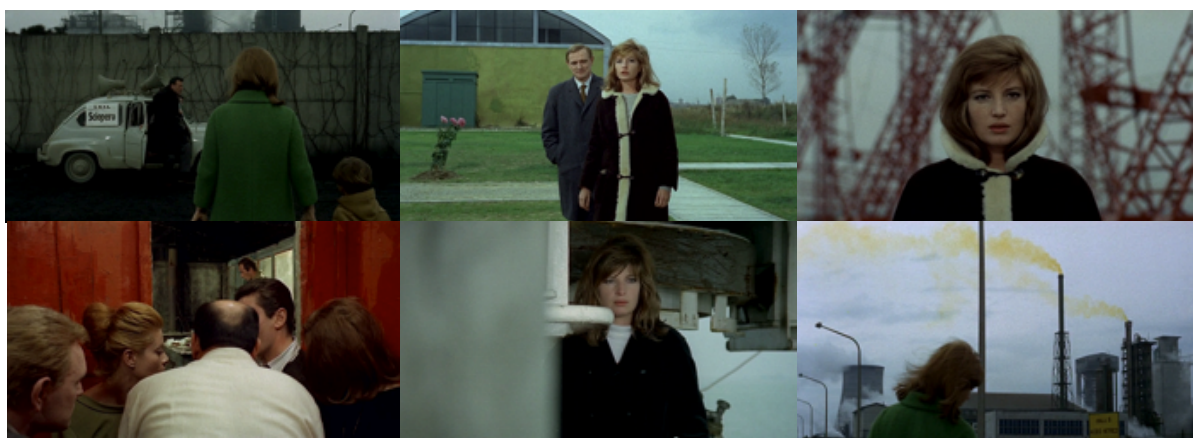

Figs. 24 a 29. O deserto vermelho

Mas não é apenas a cor o que caracteriza $O$ deserto vermelho, outra razão relevante para ter se constituído como um grande marco no que podemos chamar de cinema paisagístico, é o modo como o filme transfigura as conhecidas paisagens da região, ainda que se utilizando dos mesmos elementos e enquadramentos similares. A neblina padana e a fumaça da fábrica adensam igualmente os espaços através dos quais os personagens deambulam, mas se nos filmes comentados anteriormente a névoa servia como metáfora de uma obnubilação interior dos personagens, uma dificuldade de comunicação ou a delineação de um mood sombrio ou noir relativo ao ambiente político e social, aqui ela está próxima de uma alucinação, de uma iconografia extraterrestre, de um aspecto artificial e inautêntico, mas paradoxal e completamente ancorado na Emilia-Romagna real. São necessários apenas alguns poucos recursos para efetuar essa mutação paisagística, como a já mencionada fumaça amarela: imagens em cores que parecem de um profundo preto e branco (fig. 30); Giuliana em vistas plenamente padanas (figs. 31 e 32); Corrado caminhando pela lama (fig. 33); um barco apenas sugerido na neblina (fig. 34); Corrado caminhando em meio a uma profusão de enormes garrafas cor de turquesa tendo como fundo os ubíquos choupos secos (fig.35). Contribuíram para esse deslocamento de olhar também o uso de zoom e enquadramentos inusitados para aumentar a sensação de opressão, sobretudo na famosa sequência na cabana vermelha (fig. 27).

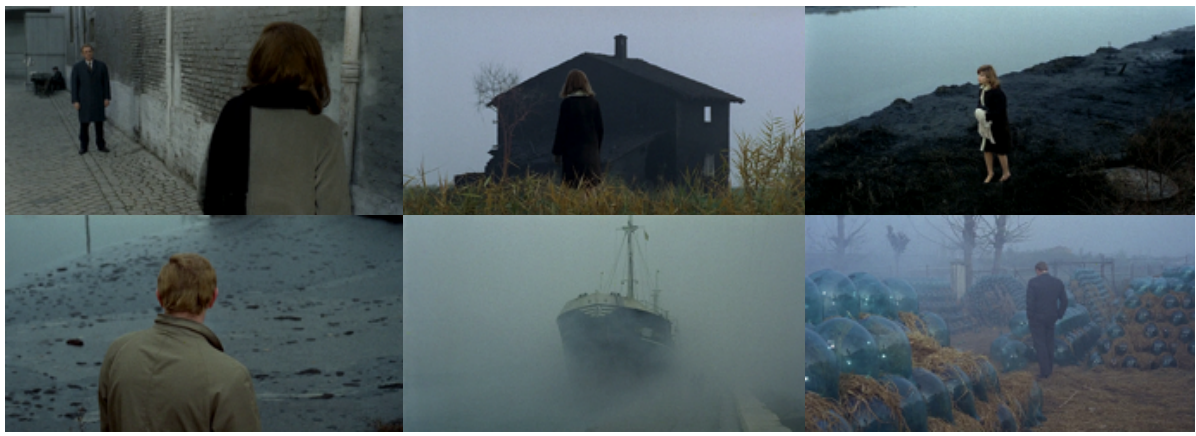

Figs. 30 a 35 . O Deserto Vermelho 
Em O Deserto Vermelho, Antonioni se aproximou verdadeiramente da pintura, usando a própria paisagem como tela, não somente pelo uso da cor ou pela abordagem excêntrica dos espaços ordinários e familiares do vale do Pó, mas por uma calculada e detalhada observação desses elementos para redirecionar nosso olhar, para encontrar beleza no design impessoal, nas linhas e curvas das fábricas, nos interiores anódinos da arquitetura moderna, nas ruínas precoces do capitalismo industrial da Itália do renascimento econômico dos anos 60 . O enorme estranhamento provocado pel' $O$ deserto vermelho talvez decorra do fato de que ele é um filme simultaneamente próximo dos preceitos neorrealistas em voga desde os anos 40 na sua precisão documental dos espaços do norte da Itália (ainda que com todos os artifícios projetados nessa documentação) e das estéticas pop da ficção científica (como por exemplo, Space men (1960) e Il Pianeta degli uomini spenti (1961), ambos de Antonio Margheriti).

\section{Os Finzi-Contini e o jardim secreto de Ferrara}

O último filme do corpus desse artigo é outra adaptação de Giorgio Bassani, O jardim dos Finzi Contini, penúltimo trabalho de Vittorio De Sica e de certo modo um desvio no seu estilo (aqui ele está próximo de algumas características viscontianas). Também ambientado em Ferrara, é um dos poucos filmes dessa época a endereçar de modo direto a perseguição dos judeus na Segunda Guerra e o papel da Itália no Holocausto. A história se concentra em um círculo de amigos no momento que começam as interdições à comunidade judaica na Itália. O jardim do título pertence à abastada família de judeus Finzi Contini ${ }^{6}$, no qual os jovens se encontram e jogam tênis depois de terem sido proibidos pelo governo fascista de circular em clubes e outros lugares de lazer da cidade. O personagem central (e espécie de comentador do destino dos demais) é Giorgio (Lino Capolicchio), judeu de classe média, apaixonado por Micól (Dominique Sanda), a herdeira dos Finzi Contini.

Assim como em A noite do massacre, a política está em forte diálogo com as motivações e implicações amorosas dos personagens. E como na adaptação prévia do conto de Bassani, Ferrara acaba por exercer um protagonismo visual muito intenso. Diferentemente dos outros filmes do conjunto, contudo, O jardim dos Finzi Contini não tem uma predominância invernal. Por compreender um longo lapso temporal, vamos ver várias estações e climas apresentados, mas bem predominantemente o verão. Os primeiros minutos do filme são uma introdução a um estilo de vida que está prestes a deixar de existir, uma despreocupação a ponto de ser extinta. De Sica filma essa iminência através da sequência do passeio de bicicletas que vai do centro da cidade até o jardim do título, em um trajeto que implica os arredores arborizados (figs. 36 a 40) e as densas folhagens do bosque padano.

6 O título do romance era "Il Giardino dei Finzi-Contini", mas na época do lançamento na Itália, Bassani demandou que o hífen fosse retirado, para marcar suas discordâncias (além do processo impetrado por ele) com De Sica com relação às alterações feitas no roteiro (O'HEALY, 2012, p. 499). 


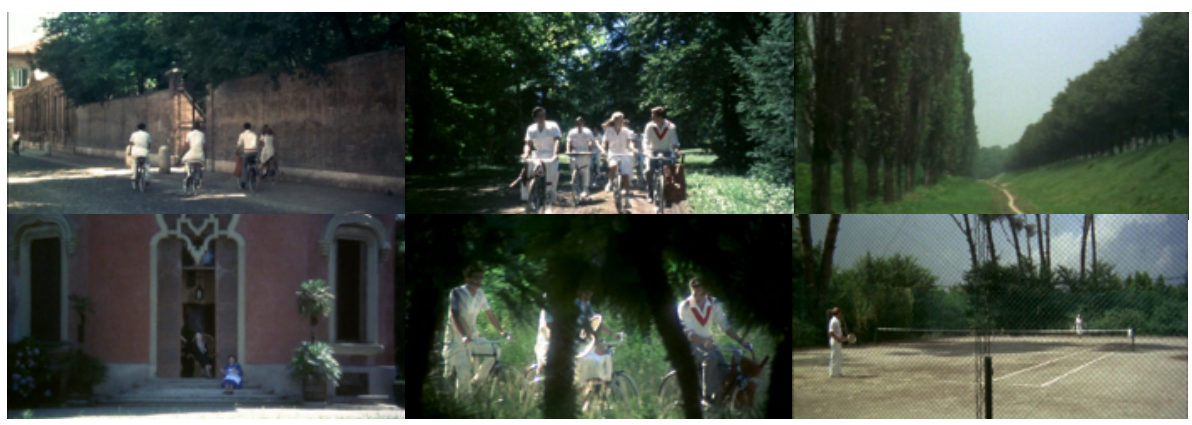

Figs. 36 a 40. O jardim dos Finzi Contini

Então, percebe-se nesse início, pelo menos, uma Ferrara aparentemente bem distinta daquela que aparecia no filme de Vancini. Porém, talvez não seja tão diferente assim. Podemos pensar em uma continuidade alternativa da obnubilação daquela invocada pela névoa: a neblina foi apenas substituída pela folhagem nessas primeiras cenas. Esse verão tem algo da elegância gélida da cidade: os jovens estão todos de branco, todos frescos e imaculados. Sem nunca mostrar de todo o jardim dos Finzi-Contini, a impressão passada por essas sequências iniciais é de uma melancolia apenas intuída, entrevista, mas nunca apresentada em um plano geral. Quase como se o jardim amuralhado [supostamente localizado na mesma rua do Palazzo dei Diamanti, o Corso Ercole I d'Este (fig. 42)] fosse um segredo compartilhado por esses amigos, sempre mostrado em segmentos, sempre implícito, sempre sugerido (figs. 41 a 43).

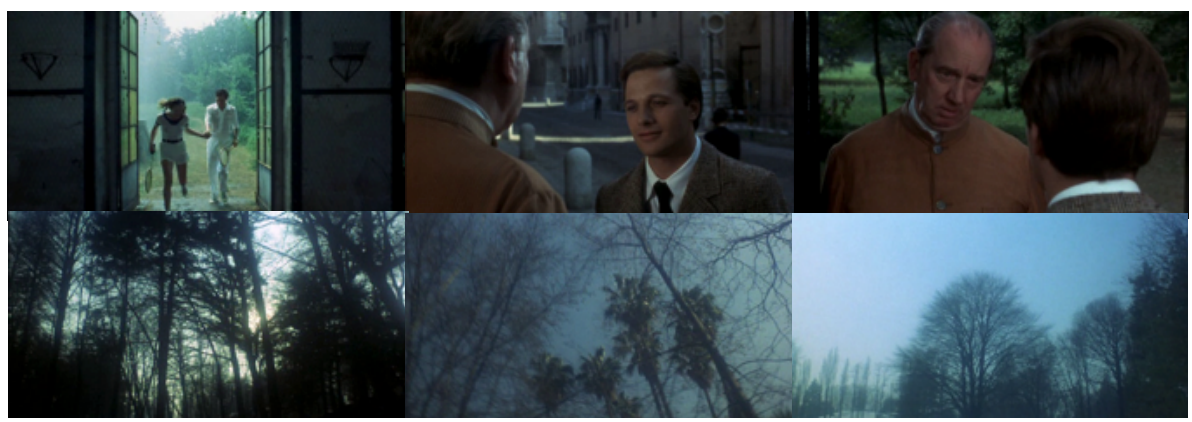

Figs. 41 a 46. O jardim dos Finzi Contini

Perto da metade, chega o inverno e com ele a neblina volta à tona. Mas à diferença dos outros filmes analisados, De Sica evita planos abertos das margens do Pó, optando por contra-plongées das árvores secas (figs. 44 a 46), quase como se ele estivesse insistindo no mistério, o mistério que é o jardim, que é Ferrara. Por isso mesmo, O jardim dos Finzi Contini não é um filme de paisagem, ou o é de modo muito mais sutil que os outros 
três longas aqui comentados. Essa apropriação dos espaços à moda de Luchino Visconti (interiores suntuosos, mansões imponentes, belas e ricas figuras humanas na paisagem) quebra a expectativa de que as vistas naturais ou urbanas possam se sobrepor ao enredo. O jardim da primeira metade do filme era um refúgio, a metáfora de um esconderijo secreto e provisório, algo fadado a desaparecer. O que de fato é mais complicado, pela própria natureza do relato, que é uma história de horror e morte. A morte, seja pela guerra, seja pelo Holocausto, ou pela doença fatal de Alberto (Helmut Berger), irmão de Micól, é iminente para quase todos os personagens do filme. E a partir do último terço do filme, Ferrara se anuncia como uma sorte de cortejo fúnebre que tem início nas comemorações pela entrada da Itália na Guerra pelas suas ruas, passa pelo funeral de Alberto no cemitério hebraico e termina nas ruas vazias e enevoadas com os últimos judeus da cidade esperando a ida para os campos de concentração (figs. 47 a 52).

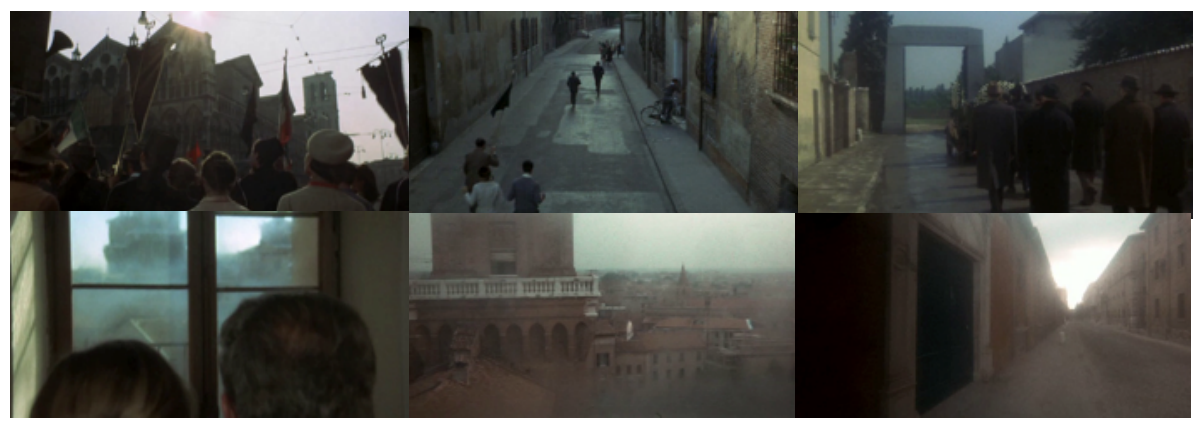

Figs. 47 a 52. O jardim dos Finzi Contini

\section{“...il viaggio finiva a Ferrara"}

Na acepção utilizada ao longo deste artigo, a paisagem é uma representação do espaço, ou, como diz Lefebvre, um predicado espacial (2006, p. 51). Assim, remete a um lugar real, a uma materialidade geográfica, a uma forma de ser do espaço externo que acaba de alguma forma colonizando nosso imaginário. A neblina, a escuridão, o jogo de luzes e sombras, a cidade invernal, as figuras solitárias frente à paisagem, esses elementos estão todos saturados de melancolia e ressoam uma espécie de estranhamento, de inquietação contemplativa. Os filmes abordados foram justamente formados por esses predicados e em contrapartida acabaram por determinar uma estética paisagística que afeta o modo como vivenciamos os lugares reais, esses pontos da Emilia-Romagna e do Vale do Pó (algumas partes do Vale ficam no Vêneto). A partir do cotejo entre os filmes, entre os outros filmes mencionados, entre outras imagens e recortes de outras artes e dos próprios conceitos revisados nas primeiras partes do artigo, as descrições apresentadas aqui buscaram delinear uma cartografia viva dessa específica paisagem italiana, investindo, assim, na materialidade desse espaço. 
Essa mesma paisagem voltaria a ser cenário de vários outros filmes depois desse ápice moderno. Antonioni, por exemplo, retorna a Ferrara em um de seus últimos trabalhos, Além das Nuvens (1995), co-dirigido por Wim Wenders. Marco Ferreri filmou também em Ferrara algumas cenas de I/ futuro è donna (1984). Ermanno Olmi faz Lungo il fiume (1992), um documentário sobre o Pó (no qual ângulos e recortes semelhantes aos vistos anteriormente reaparecerão destacados por um texto que mescla ecologia, antropologia e certo misticismo), e I/ mestiere delle arme (2001), relato histórico sobre Giovanni de Medici, ambientado em parte na Ferrara do século XVI (muitas cenas em palácios e castelos da região) e nas planícies enevoadas nas margens do rio. Obras menos célebres como Notte italiana (1987), de Carlo Mazzacurati, Gli occhiali d'oro (1987) - também baseado em obra de Bassani -, de Giuliano Montaldo ou Amore tra le rovine (2015), de Massimo Ali Mohammad, entre vários outros, voltariam ao Vale do Pó e a Ferrara. Todos esses filmes lidaram com uma concepção visual parecida à dos filmes do nosso recorte, quase todos recorreram aos lugares e atmosferas nas quais prevalece um engajamento melancólico com um espaço. Neles também a neblina foi uma sorte de operador estilístico para concretizar essa imagem mental.

Foi assim, a "pálida, pálida neblina" do poema de Tonino Guerra, que nos foi guiando na busca pelos contornos de uma paisagem autônoma nos filmes comentados aqui, que, para além das maneiras particulares com que cada um deles realizou a representação espacial (formas audiovisuais vinculadas a uma concepção profundamente moderna tanto de cinema como de interpretação e crítica do espaço que eles apresentam), formam um conjunto complexo e poético de um lugar. Eles se aproximam da noção de paisagem como uma unidade entre pessoas e o mundo, como um espaço subjetivo, vivido e compartilhado por gente, e, ao mesmo tempo, marcado por uma especificidade pictórica e uma materialidade intricada e complexa que sugere a possibilidade de afirmação de um gênero paisagístico para o cinema, tão vibrante e nuançado quanto a paisagem na pintura.

Ângela Freire Prysthon é professora titular do Departamento de Comunicação Social da UFPE.

prysthon@gmail.com

\section{Referências}

ANDREWS, M. Landscape and Western Art. Oxford: Oxford University Press, 1999.

BERGER. J. Landscapes: John Berger on Art. London: Verso, 2016.

BERNARDI, S. Il paesaggio nel cinema italiano. Venezia: Marsilio, 2002. 
BOWRING, J. Melancholy and the landscape: locating sadness, memory and reflection in the landscape. New York: Routledge, 2017.

BRUNO, G. Atlas of Emotion: Journeys in Art, Architecture, and Film. London: Verso, 2002.

DELEUZE, G. A imagem-tempo. São Paulo: Brasiliense, 1990.

GUMBRECHT, H. U. Atmosfera, ambiência, Stimmung. Rio de Janeiro: Contraponto/ Editora PUC-RIO, 2014.

KRACAUER, S. Theory of Film: The Redemption of Physical Reality. Princeton: Princeton University Press, 1997.

LEFEBVRE, M. (org.). Landscape and Film. London: Routledge, 2006.

MICALLIZZI, P. Florestano Vancini. Fra cinema e televisone. Ravenna: A. Longo, 2002.

NANCY, J. L. The Ground of the Image. New York: Fordham University Press, 2005.

O'HEALY, Á. Vittorio De Sica in The Garden of the Finzi-Continis: notes from an American Classroom. In: ANTOGNINI, R. e BLUMENFELD, R. (orgs.). Poscritto a Giorgio Bassani. New York: LED, 2012. p. 499-516.

SINNEBRINK, R. Stimmung: exploring the aesthetics of mood. Screen 53:2, 2012, p. 148-163.

STILGOE, J. Landschaft and Linearity: Two Archetypes of Landscape. Environmental Review: ER, vol. 4, n. 1, p. 2-17, 1980. 